\title{
Preoperative breast magnetic resonance imaging in patients with ductal carcinoma in situ: a systematic review for the European Commission Initiative on Breast Cancer (ECIBC)
}

\author{
Carlos Canelo-Aybar ${ }^{1,2} \cdot$ Alvaro Taype-Rondan $^{3}$ - Jessica Hanae Zafra-Tanaka ${ }^{4}$. David Rigau ${ }^{2} \cdot$ Axel Graewingholt $^{5}$. \\ Annette Lebeau ${ }^{6}$ - Elsa Pérez Gómez ${ }^{7}$ Paolo Giorgi Rossi ${ }^{8} \cdot$ Miranda Langendam $^{9}$ - Margarita Posso ${ }^{2,10}$. \\ Elena Parmelli ${ }^{11}$ (D) Z Zuleika Saz-Parkinson ${ }^{11} \cdot$ Pablo Alonso-Coello ${ }^{1,2}$
}

Received: 23 October 2020 / Revised: 18 February 2021 / Accepted: 11 March 2021 / Published online: 30 May 2021

(C) The Author(s) 2021, corrected publication 2021

\begin{abstract}
Objective To evaluate the impact of preoperative MRI in the management of Ductal carcinoma in situ (DCIS).

Methods We searched the PubMed, EMBASE and Cochrane Library databases to identify randomised clinical trials (RCTs) or cohort studies assessing the impact of preoperative breast MRI in surgical outcomes, treatment change or loco-regional recurrence. We provided pooled estimates for odds ratios (OR), relative risks (RR) and proportions and assessed the certainty of the evidence using the GRADE approach.

Results We included 3 RCTs and 23 observational cohorts, corresponding to 20,415 patients. For initial breast-conserving surgery (BCS), the RCTs showed that MRI may result in little to no difference (RR 0.95, 95\% CI 0.90 to 1.00 ) (low certainty); observational studies showed that MRI may have no difference in the odds of re-operation after BCS (OR 0.96; 95\% CI 0.36 to 2.61) (low certainty); and uncertain evidence from RCTs suggests little to no difference with respect to total mastectomy rate (RR $0.91 ; 95 \%$ CI 0.65 to 1.27 ) (very low certainty). We also found that MRI may change the initial treatment plans in $17 \%(95 \% \mathrm{CI}$ 12 to $24 \%$ ) of cases, but with little to no effect on locoregional recurrence (aHR $=1.18 ; 95 \%$ CI 0.79 to 1.76 ) (very low certainty). Conclusion We found evidence of low to very low certainty which may suggest there is no improvement of surgical outcomes with pre-operative MRI assessment of women with DCIS lesions. There is a need for large rigorously conducted RCTs to evaluate the role of preoperative MRI in this population.

Key Points

- Evidence of low to very low certainty may suggest there is no improvement in surgical outcomes with pre-operative MRI.

- There is a need for large rigorously conducted RCTs evaluating the role of preoperative MRI to improve treatment planning for DCIS.
\end{abstract}

Keywords Breast cancer $\cdot$ Ductal carcinoma in situ $\cdot$ Magnetic resonance imaging

\footnotetext{
Carlos Canelo-Aybar

ccanelo@santpau.cat

$\triangle$ Elena Parmelli

Elena.Parmelli@ec.europa.eu
}

1 CIBER de Epidemiología y Salud Pública (CIBERESP), Madrid, Spain

2 Iberoamerican Cochrane Centre - Department of Clinical Epidemiology and Public Health, Biomedical Research Institute Sant Pau (IIB Sant Pau), Sant Antonio María Claret 167, 08025 Barcelona, Spain

3 Universidad San Ignacio de Loyola, Unidad de Investigación para la Generación y Síntesis de Evidencias en Salud, Lima, Peru

4 CRONICAS Centre of Excellence in Chronic Diseases, Universidad Peruana Cayetano Heredia, Lima, Peru
5 Radiologie am Theater, Paderborn, Germany

6 Institute of Pathology, University Medical Center Hamburg-Eppendorf, Hamburg, Germany

7 University Hospital Dr. Josep Trueta, Girona, Spain

8 Epidemiology Unit, Azienda USL - IRCCS di Reggio Emilia, Reggio Emilia, Italy

9 Department of Epidemiology and Data Science, Amsterdam UMC, University of Amsterdam, Amsterdam Public Health Institute, Amsterdam, Netherlands

10 Department of Epidemiology and Evaluation, IMIM (Hospital del Mar Medical Research Institute), Barcelona, Spain

11 European Commission, Joint Research Centre (JRC), Via E. Fermi, 2749. TP127, I-21027 Ispra, VA, Italy 


\begin{tabular}{|c|c|}
\hline \multicolumn{2}{|c|}{ Abbreviations } \\
\hline $\mathrm{aOR}$ & Adjusted odds ratios \\
\hline $\mathrm{BCS}$ & Breast-conserving-surgery \\
\hline DCIS & Ductal carcinoma in situ \\
\hline ECIBC & $\begin{array}{l}\text { European Commission Initiative } \\
\text { on Breast Cancer }\end{array}$ \\
\hline GDG & Guidelines Development Group \\
\hline IBC & Invasive breast carcinomas \\
\hline MRI & Magnetic resonance imaging \\
\hline OR & Odds ratios \\
\hline $\mathrm{PICO}$ & $\begin{array}{l}\text { Population, Intervention, Comparison } \\
\text { and Outcomes }\end{array}$ \\
\hline RCTs & Randomised clinical trials \\
\hline ROBINS-I & $\begin{array}{l}\text { Risk Of Bias in Non-randomised } \\
\text { Studies of Interventions-I }\end{array}$ \\
\hline $\mathrm{RR}$ & Relative risks \\
\hline SoF & Summary of findings \\
\hline
\end{tabular}

\section{Introduction}

In 2018, globally, an estimated 2 million new cases of breast cancer (BC) were reported [1]. Ductal carcinoma in situ (DCIS) of the breast is the most common form of noninvasive $\mathrm{BC}$, and includes a heterogeneous group of atypical cell proliferation confined within the basement membrane of the ducts [2]. Over the last decades, the detection of DCIS has increased, likely because of the widespread use of screening mammography, accounting for 20 to $25 \%$ of newly diagnosed $\mathrm{BC}$ in screened populations [3].

Nowadays, breast-conserving surgery (BCS) has been adopted as a treatment option for patients with small, screendetected lesions [4]. The addition of adjuvant radiation and hormonal therapy after BCS has been shown to reduce the risk of invasive recurrence [4]. However, complete surgical excision is not always possible due to the suboptimal preoperative evaluation of the extent of the lesion by standard imaging (mammography, ultrasound). Therefore, re-operation for positive margins is often required in DCIS, with rates ranging from 17 to $58 \%$ [5].

Magnetic resonance imaging (MRI) has a higher sensitivity for $\mathrm{BC}$ diagnosis preferentially detecting more aggressive/ invasive types [6]. It has been proposed as an additional test after mammography, to improve the assessment of the extent of DCIS during the preoperative planning, providing better identification of candidates for BCS especially in the context of extensive microcalcifications [7]. Despite previous reviews suggesting MRI benefits [8-10], there is still uncertainty as some studies suggest it may overestimate the extent of disease, leading to an increase of unnecessary mastectomies or wider excisions $[11,12]$.

The European Commission Initiative on Breast Cancer (ECIBC) develops the European Guidelines on Breast Cancer Screening and Diagnosis [13]. This systematic review informed the recommendations of preoperative breast MRI (Prospero register: 42018099453). During the guidelines process [13], the Guidelines Development Group (GDG) made detailed considerations on the evidence about effects, values and preferences, equity, acceptability and feasibility to issue recommendations. We encourage readers to refer to these considerations in the published recommendations on the ECIBC website (https://healthcare-quality.jrc.ec.europa.eu/europeanbreast-cancer-guidelines/surgical-planning/MRI)

\section{Methods}

\section{Structured question and outcome prioritisation}

The clinical question prioritised by the GDG was "Should additional MRI vs no additional MRI be used in women with histologically confirmed DCIS for preoperative planning?".

Outcomes were prioritised using a 1 to 9 scale as suggested by the Grading of Recommendations Assessment, Development and Evaluation (GRADE) approach (Box 1).

Box 1 Structured clinical question

\begin{tabular}{|c|c|c|c|}
\hline Population & Intervention & Comparison & Outcomes \\
\hline $\begin{array}{l}\text { Women with } \\
\text { confirmed } \\
\text { DCIS on } \\
\text { preoperative } \\
\text { histology }\end{array}$ & $\begin{array}{l}\text { Preoperative } \\
\text { breast } \\
\text { MRI }\end{array}$ & $\begin{array}{l}\text { No } \\
\text { preopera- } \\
\text { tive breast } \\
\text { MRI }\end{array}$ & $\begin{array}{l}\text { - MRI triggered } \\
\text { treatment change, as } \\
\text { the decision to } \\
\text { perform a wider } \\
\text { excision, a } \\
\text { mastectomy or a } \\
\text { bilateral } \\
\text { mastectomy when a } \\
\text { more conservative } \\
\text { approach were } \\
\text { originally planned } \\
\text { before MRI results } \\
\text { - Initial } \\
\text { breast-conserving } \\
\text { surgery (BCS), a } \\
\text { patient not undergo- } \\
\text { ing mastectomy } \\
\text { within the initial } \\
\text { surgical treatment } \\
\text { - Re-operation after } \\
\text { breast-conserving } \\
\text { surgery, either a } \\
\text { wider local excision } \\
\text { or mastectomy after } \\
\text { the first surgery } \\
\text { - Proportion of } \\
\text { positive margins } \\
\text { after } \\
\text { breast-conserving } \\
\text { surgery, absence of } \\
\text { clear margins at the } \\
\text { pathologic assess- } \\
\text { ment of the }\end{array}$ \\
\hline
\end{tabular}




\section{(continued)}

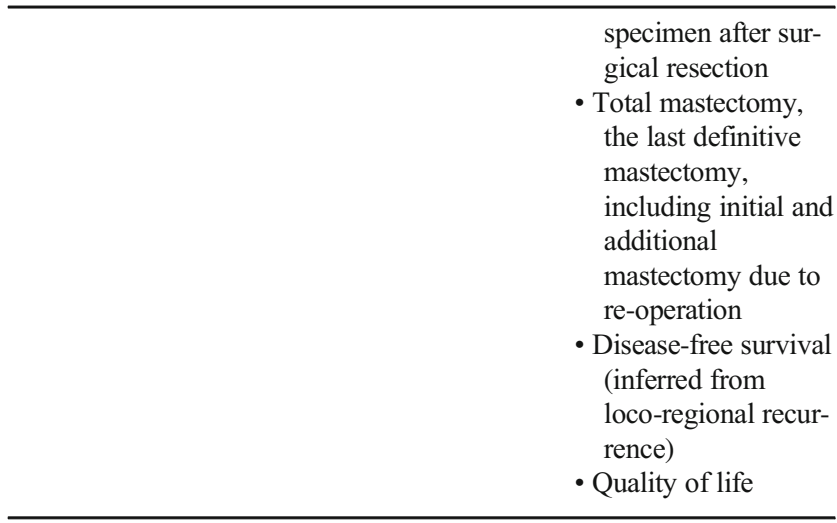

${ }^{\mathrm{a}} \mathrm{An}$ increase in this outcome is a desirable change as it is a complementary event to initial mastectomy

\section{Data sources and searches}

We searched the MEDLINE (via PubMed, April 2018), EMBASE (via Ovid, April 2018) and CENTRAL (via The Cochrane Library, March 2018) databases using pre-defined algorithms. In addition, we updated our initial search during the first week of January 2021 (Supplementary Table 1), and GDG members were consulted about potential missing studies.

\section{Study selection}

We included randomised controlled trials (RCT) and cohort studies that compared preoperative MRI with no MRI in women with histologically confirmed DCIS. We excluded studies that included women with invasive breast carcinomas (IBC), those that did not provide stratified results for women with DCIS, conference abstracts and articles published in languages other than English.

Initially, two calibrated reviewers (A.T.R. and J.Z.) assessed the eligibility at title and abstract level. In a second step, the two reviewers independently reviewed the full text of all the selected references. Discrepancies were solved by consensus or with the help of a third reviewer (CCA).

\section{Data extraction and risk of bias assessment}

Three reviewers (A.T.R., J.Z., C.C.A.) independently extracted data and assessed the risk of bias using the Cochrane Risk of Bias tool [14] for RCTs and the "Risk Of Bias in Nonrandomised Studies of Interventions-I" (ROBINS-I) for observational studies. Before applying the latter tool, we specified relevant confounding variables (i.e. age, family history of $\mathrm{BC}$, tumour size) [15].

\section{Data analysis}

From RCTs, we extracted crude relative risks (RR), and from observational studies, we obtained adjusted odds ratios (aOR) or hazard ratios (aHR) when available. We did not pool the results obtained from both types of designs. Pooled effect sizes were estimated using a random effects model with the Mantel-Haenzel or inverse variance method. To estimate between-study variance and confidence intervals, we used the Paule-Mendel and Q-profile methods. To pool the proportion of MRI-treatment changes, we implemented a generalised linear mixed random model with a logit transformation, and the Clopper-Pearson method to estimate the confidence interval for individual study results.

Heterogeneity between studies was evaluated by visual inspection of forest plots for all outcomes and complemented with the assessment of the $Q$ statistic and $I^{2}$ parameter for relative effects, as they are not recommended for proportions [16]. The following potential sources of heterogeneity were examined: the extent of microcalcifications, risk of bias, adjusted or crude effect sizes, prospective or retrospective design for observational studies and publication year (post hoc). We performed all analysis in RStudio.

\section{Certainty of the evidence}

We rated the certainty of the evidence separately for RCTs and observational studies for each of the prioritised outcomes using the GRADE approach [17]. For the assessment of the certainty of observational evidence, we started from high certainty, as this is the recommended procedure when the ROBINS-I tool is used [18].

\section{Results}

\section{Search results}

In the initial search until April 2018, we retrieved 5260 unique citations. Initially, we included a total of 20 studies; this was the original evidence synthesis used to develop the ECIBC recommendations. Finally, after the update search (January 2021), we included six additional studies and the update of a previously included cohort (Fig. 1). Reasons for exclusion are detailed in Supplementary table S2.

\section{Study characteristics}

Three studies were RCTs [19-21], 18 were comparative cohorts $[11,12,22-36]$ and five were single arm cohorts $[12,21$, $37-39]$, with a total of 20,415 patients (260 from the RCTs and 20,155 from the observational studies). Most studies were conducted in the USA or in the Netherlands. The mean ages of 


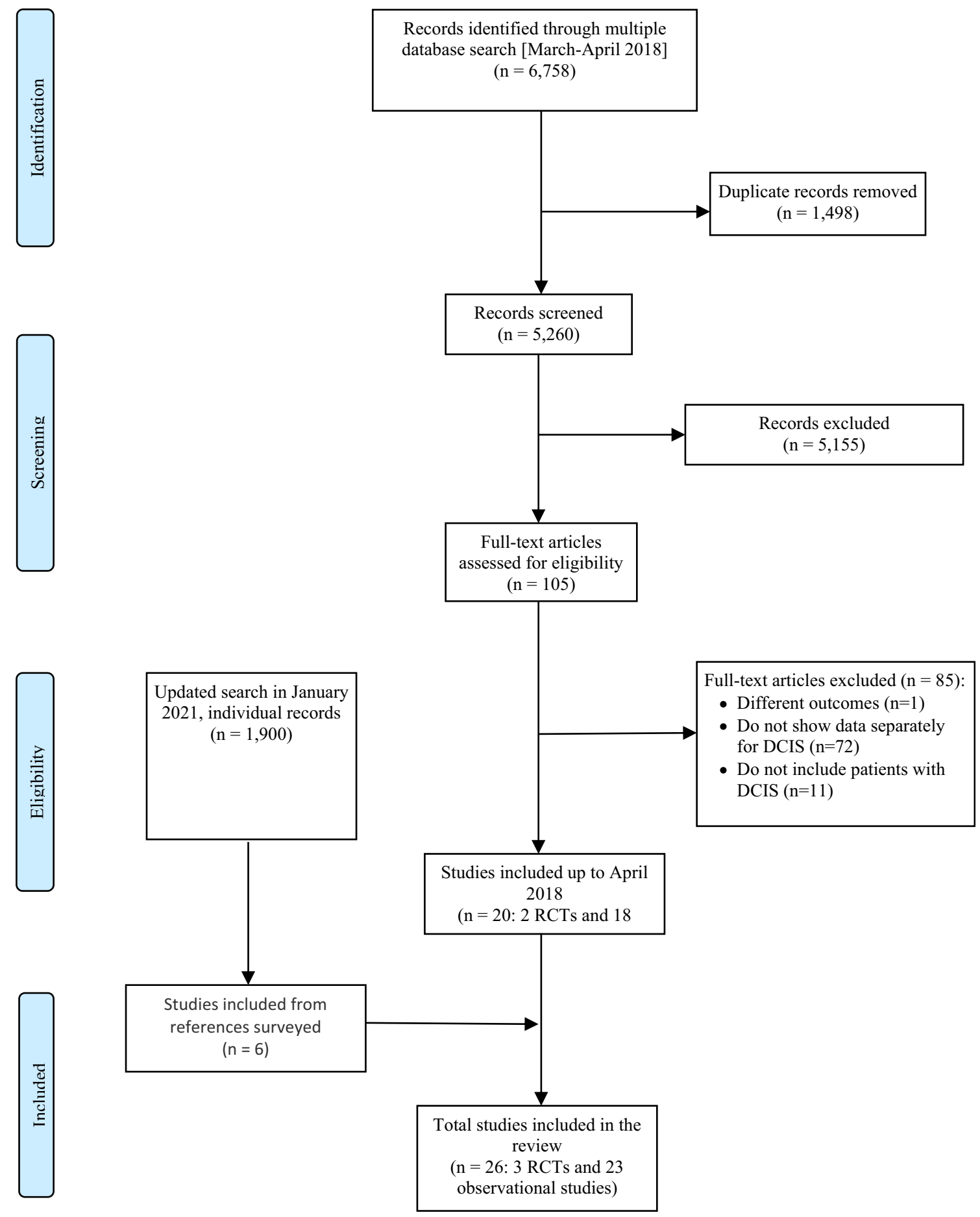

Fig. 1 Flowchart of study selection

the recruited patients ranged from 40 to 63 years across all studies. Only one study included all patients with microcalcified lesions, while two studies reported the percentage of microcalcified lesions (range 76 to 99\%) (Table 1 and Supplementary table S3).

One RCT was purposely designed to evaluate the value of breast MRI in patients with biopsy-proven DCIS who were scheduled for BCS [21], with almost all lesions presenting microcalcifications and a mean size of $10 \mathrm{~mm}$. Additionally, we included data from small subgroups of patients with DCIS from two RCTs, the MONET trial [19] which randomised patients with a non-palpable BIRADS 3-5 lesion to receive routine medical care (mammography, ultrasound and lesion sampling) or additional MRI preceding biopsy and the multicentric COMICE trial [20] which recruited patients with biopsy-proven primary 


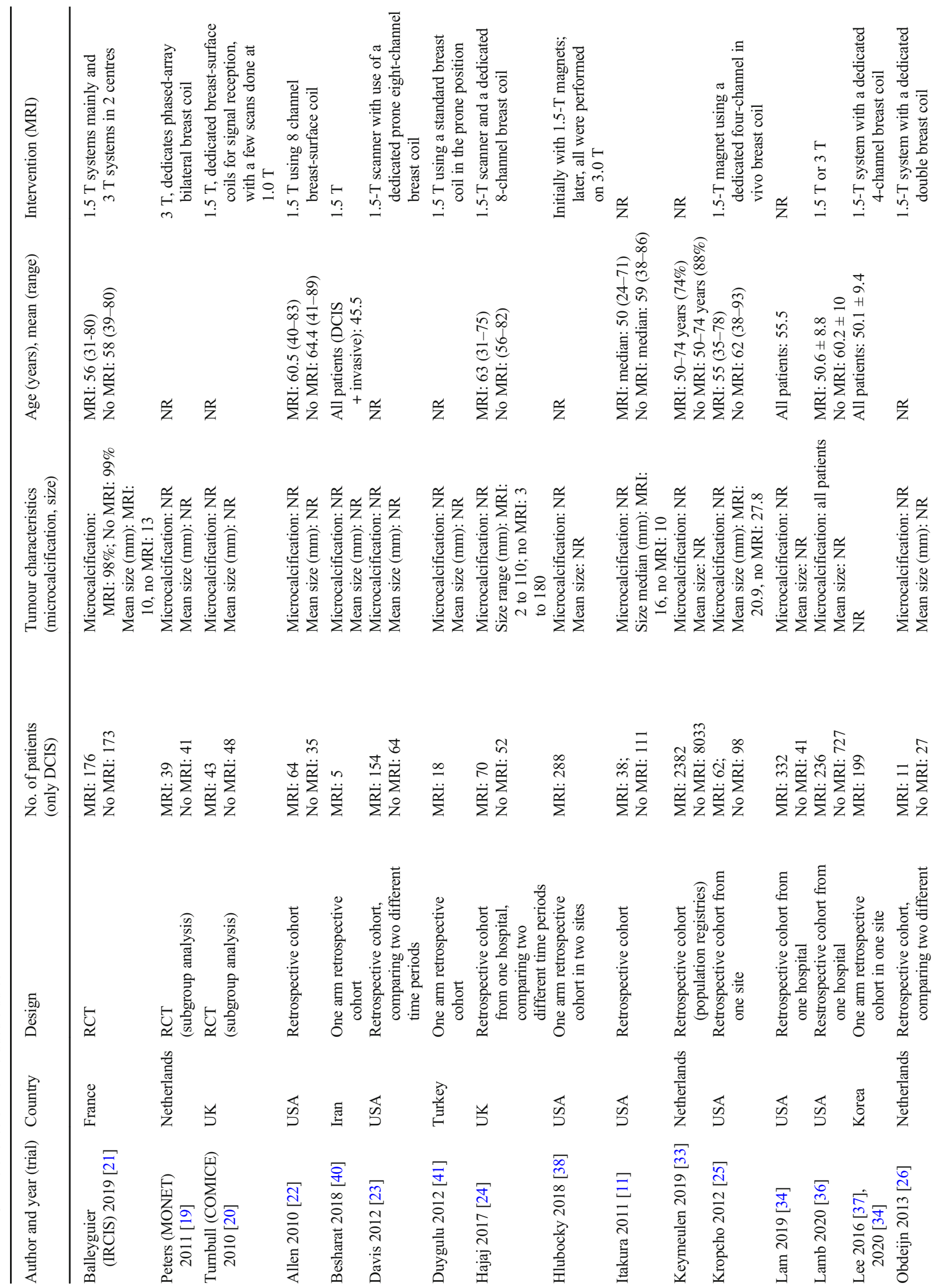




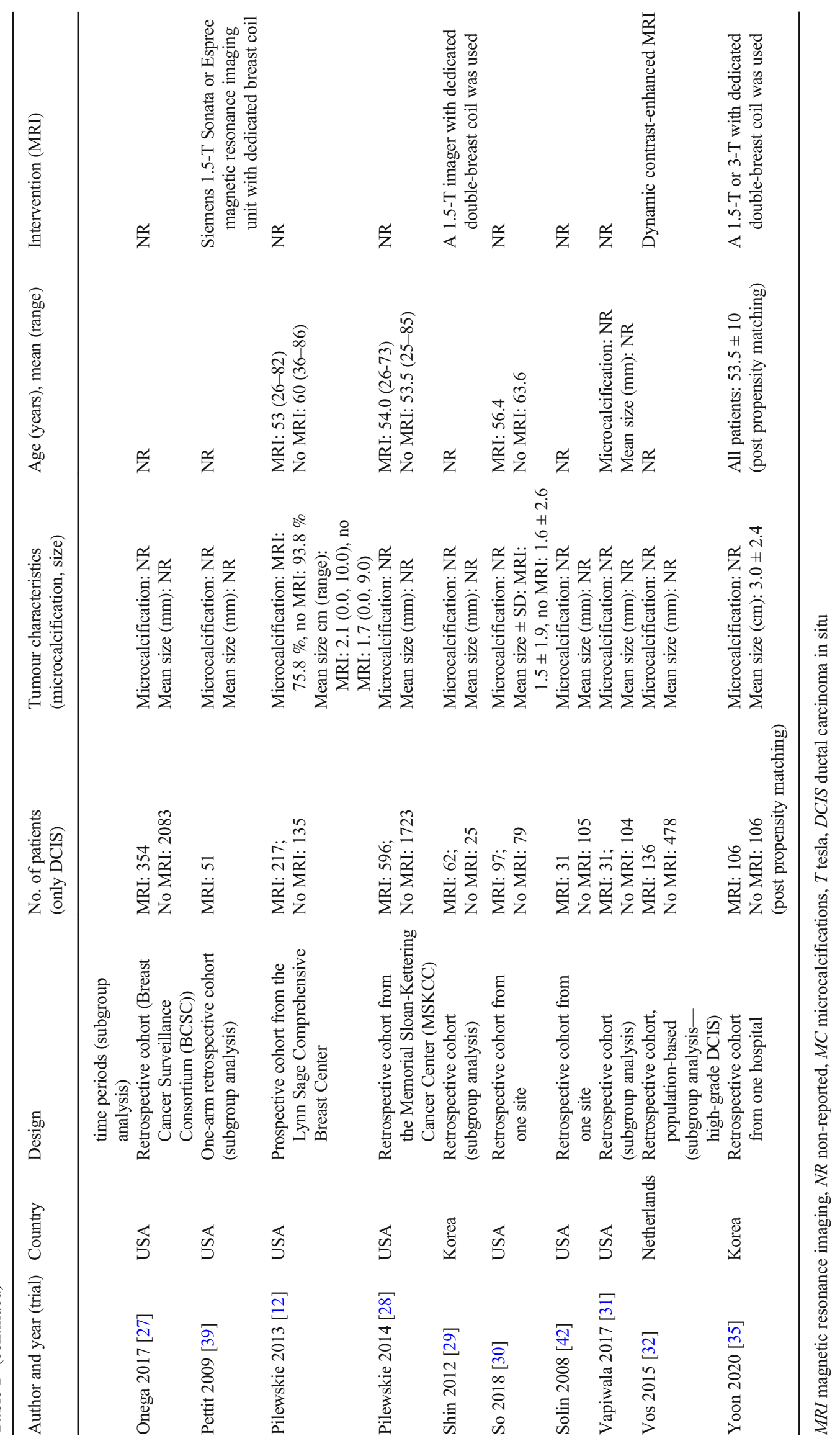


$\mathrm{BC}$ who had undergone triple assessment, and were scheduled for a wide local excision.

Of the 18 comparative cohorts included [11, 12, 22-34], 16 were retrospective analyses of medical records or population registries [11, 12, 22-27, 29-36], three of them comparing different time periods (pre- and post-implementation of MRI) [23, $24,26]$. Three cohort studies had larger sample sizes, one used the Breast Cancer Surveillance Consortium registry data with 2437 patients with DCIS from 2010 to 2014 [27], another study included data of 2319 patients from a cancer centre in New York (USA) from 1997 to 2010 [28] and the last study used the Netherlands Cancer Registry (NCR) including 10,415 clinical records [33] (Table 1 and Supplementary table S3).

We also included five single MRI-arm cohorts [37-41] and the MRI arm of three comparative cohorts and one RCT [12, 21, 26], where all surgical treatment changes due to the MRI findings were recorded. We did not find studies directly reporting the quality of life of patients receiving pre-operative breast MRI.

\section{Initial BCS}

Two RCTs, including a total of 429 patients, showed that MRI may result in little to no difference in initial BCS (RR 0.95; 95\% CI 0.90 to 1.00) (Fig. 2a) (low certainty) [19, 21]. In 11 observational studies [11, 12, 22-24, 27, 32-36], the odds of BCS was lower but the evidence was very uncertain (OR $0.49 ; 95 \%$ CI 0.29 to 0.82 ) and only two cohort studies reported adjusted OR showing similar results (very low certainty) $[32,35]$ (Fig. 2b).

\section{Proportion of positive margins (after undergoing BCS)}

The results from 91 patients in one RCT suggested that MRI may increase the risk of positive margins in the excised lesion (RR of $1.58 ; 95 \%$ CI 0.88 to 2.92) (very low certainty) [20]. However, from observational studies, the pooled analysis including 9126 patients suggested that MRI pre-operative assessment may have little to no difference in this outcome (OR 0.91 ; 95\% CI 0.85 to 1.21 ) [11, 22, 25, 26, 28, 32, 33, 35] (very low certainty). It is noteworthy that the definitions for positive margins across studies were heterogenous (i.e. < $1 \mathrm{~mm}[11,27]$ or $<5 \mathrm{~mm}$ [29]) or not clearly described [36], even among the included centres of the only RCT reporting this outcome [20].

\section{Re-operation rate (after undergoing BCS)}

Two RCTs suggested no difference in the risk of having a reoperation after an initial BCS (RR 1.02; 95\% CI 0.56 to 1.84 ), but the evidence was uncertain (very low certainty) $[19,21]$. The pooled estimate from 12 observational studies suggested a decrease in the risk of re-operation (OR $0.72 ; 95 \%$ CI 0.50 to 1.04) (Fig. 3b) [11, 12, 22-26, 29, 30, 32-36].
The observational studies providing adjusted estimates had an inconsistent effect (OR 0.96; 95\% CI 0.36 to 2.61) [30, 32, $35]$ compared to studies with unadjusted estimates (OR 0.66; $95 \%$ CI 0.45 to 0.99 ). Therefore, only those providing adjusted estimates were included in the evidence profile for observational studies (low certainty). One study reported the mean number of re-operations among those patients who received lumpectomy and showed no relevant differences $(0.42$ vs $0.58, p$ value $=0.31)[11]$.

\section{Total mastectomy}

Two RCTs, including 429 patients [19, 21], showed that MRI may result in little to no difference in total mastectomy surgeries (RR 0.91; 95\% CI 0.65 to 1.27), equivalent to 21 fewer total mastectomies (95\% CI 82 fewer to 63 more) performed per 1000 patients assessed (very low certainty) (Table 2). Eight observational studies suggested that MRI may increase the odds of total mastectomies (OR 1.58; 95\% CI 1.00 to 2.48) (very low certainty) (Fig. 4b) [12, 22, 23, 25, 32-35], with a larger but imprecise effect observed in studies providing adjusted results (aOR 1.74; 95\% CI 0.53 to 5.68) [32, 35].

\section{Disease-free survival (inferred from locoregional recurrence)}

One study reported a subgroup of 135 patients with DCIS, over a follow-up of 10 years, and found no differences in disease-free survival between the use or not of breast MRI $(4 \%$ vs $4 \%, p$ value $=0.25)[31]$. Another study reported similar results at 8 years of follow-up for the rate of any local failure among 136 patients $(6 \%$ vs $6 \%, p$ value $=0.58)$ [42]. Lamb et al reported similar rates of second $\mathrm{BC}$ events whether MRI was used or not (12.8\% versus $11.5 \%, p=0.68)$ [36].

The largest study, which included 2212 patients with a median follow-up of 4.9 years, showed, in an adjusted multivariate analysis (i.e. age, margin status, number of excisions), that MRI may increase the risk of local recurrence $(\mathrm{aHR}=$ $1.18 ; 95 \%$ CI 0.79 to 1.76 ) (very low certainty) [28].

\section{MRI triggered treatment change}

Eight cohorts $[12,26,33,35,37-41]$ and the intervention arm of one RCT [21] informed this outcome. Our pooled estimation showed that $17 \%$ (95\% CI 12 to $24 \%$ ) of the initial surgical decisions may change to a more extensive resection or mastectomy when breast MRI is used (low certainty) (Supplementary Figure 2). There was important heterogeneity, with the five studies with a larger sample size $[12,21,37-39]$ reporting between 9 and $18 \%$ and those with a smaller sample size reporting much higher proportions (39\% [41] to 50\% [26]). 


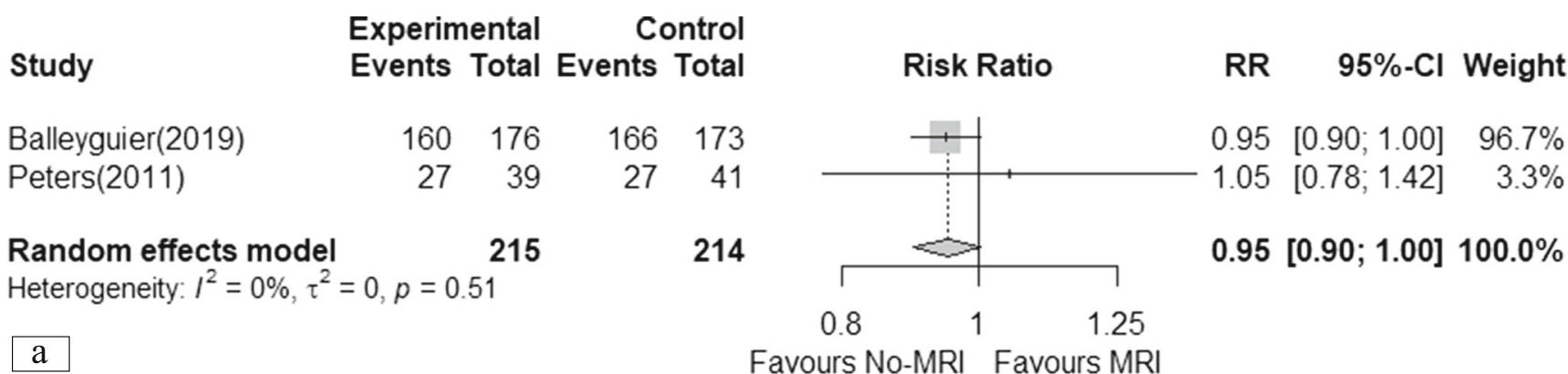

\section{Study}

Allen(2010)

Davis(2012)

Hajaj(2017)

Itakura(2011)

Keymeulen(2019)

Lam(2020)

Lamb(2020)

Onega(2017)

Pilewskie(2013)

Vos(2015)

Yoon(2020)
TE seTE

$\begin{array}{lll}0.41 & 0.5021\end{array}$

$\begin{array}{lll}-0.13 & 0.3768\end{array}$

$\begin{array}{lll}-3.28 & 0.7597\end{array}$

$\begin{array}{lll}-1.78 & 0.4222\end{array}$

$\begin{array}{lll}-0.94 & 0.0487\end{array}$

$\begin{array}{lll}-0.13 & 0.3549\end{array}$

$\begin{array}{lll}-0.78 & 0.1661\end{array}$

$\begin{array}{lll}-0.46 & 0.1213\end{array}$

$\begin{array}{lll}-0.34 & 0.2400\end{array}$

$\begin{array}{lll}-1.16 & 0.2122\end{array}$

$\begin{array}{ll}-0.16 & 0.2867\end{array}$

Favours No-MRI Favours MRI

\section{Random effects model}

Heterogeneity: $I^{2}=82 \%, \tau^{2}=0.6564, p<0.01$

$\begin{array}{lllll}0.01 & 0.1 & 1 & 10 & 100\end{array}$

Favours No-MRI Favours MRI
OR $\quad 95 \%-\mathrm{Cl}$ Weight

$1.50[0.56 ; 4.01] \quad 7.7 \%$

$0.88[0.42 ; 1.84] \quad 8.8 \%$

$0.04[0.01 ; 0.17] \quad 5.7 \%$

$0.17[0.07 ; 0.39] \quad 8.4 \%$

$0.39[0.35 ; 0.43] \quad 10.6 \%$

$0.88[0.44 ; 1.76] \quad 8.9 \%$

$0.46[0.33 ; 0.64] \quad 10.2 \%$

$0.63[0.50 ; 0.80] \quad 10.4 \%$

$0.71[0.45 ; 1.14] \quad 9.8 \%$

$0.31[0.21 ; 0.48] \quad 10.0 \%$

$0.85[0.48 ; 1.49] \quad 9.5 \%$

ery. a Randomised clinical trial; b cohort studies (prospective and retrospectives)

\section{Subgroup and sensitivity analysis}

One RCT and 11 observational studies reported the age of participants which was similar across studies. We were not able to perform subgroup analysis on the extent of microcalcifications as most studies did not provide detailed data, but we included a post hoc analysis comparing those studies that reported the proportion of patients with microcalcification lesions with those that did not.

As described above (see "Re-operation rate (after undergoing BCS)"), we found different estimates among observational studies reporting adjusted versus crude estimates for reoperations but with overlapping confidence intervals (test for subgroup differences $p$ value $=0.499$ ). Other subgroup analyses, including publication year, did not show meaningful results (Supplementary table S4).

\section{Risk of bias and certainty of the evidence}

The included RCTs did not blind participants nor the clinical personnel leading to a potential risk of performance bias as treatment decisions might have been influenced by the knowledge of the allocation arm. The assessment of surgical outcomes is less likely to be biased due to unblinded assessment. However, the evaluation of positive margins in the surgical excised specimens might be at higher risk of bias as described elsewhere [43].

In addition, two of the three RCTs might be subject to an imbalance of prognosis factors, as we included results for small subgroups of the originally allocated patients $[19,20]$. The probability of important imbalance for a single prognostic factor is higher in RCTs with less than 100 participants [44, 45].

For observational evidence, our main concern was risk of bias, as only three studies reported adjusted estimates [28, 30, 32]. Confounding variables (i.e. age, lesion size on mammography) might be associated to requesting breast MRI and to performing more aggressive surgical treatments. Most observational studies were retrospective and potentially subject to loss of follow-up or misrecorded data. Three studies compared two different time periods which may lead to bias related to 


\begin{tabular}{lrrrr}
\hline Study & \multicolumn{3}{c}{$\begin{array}{c}\text { Experimental } \\
\text { Events }\end{array}$} & \multicolumn{3}{c}{$\begin{array}{c}\text { Control } \\
\text { Total Events }\end{array}$} \\
Balleyguier(2019) & 35 & 157 & 47 & 165 \\
Peters(2011) & 15 & 28 & 10 & 27 \\
Random effects model & & 185 & & 192 \\
Heterogeneity: $I^{2}=65 \%, \tau^{2}=0.1229, p=0.09$ & & \\
a &
\end{tabular}

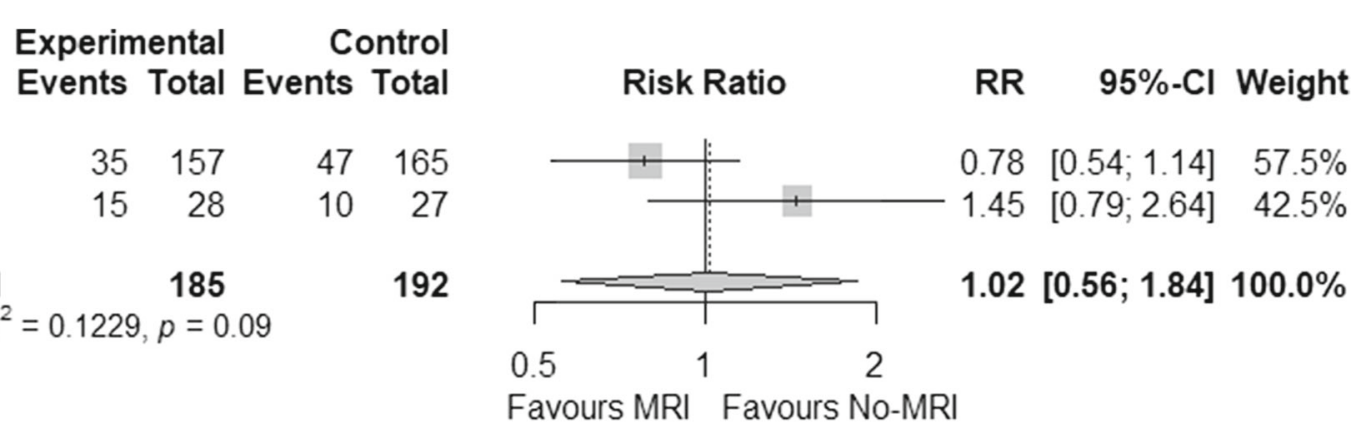

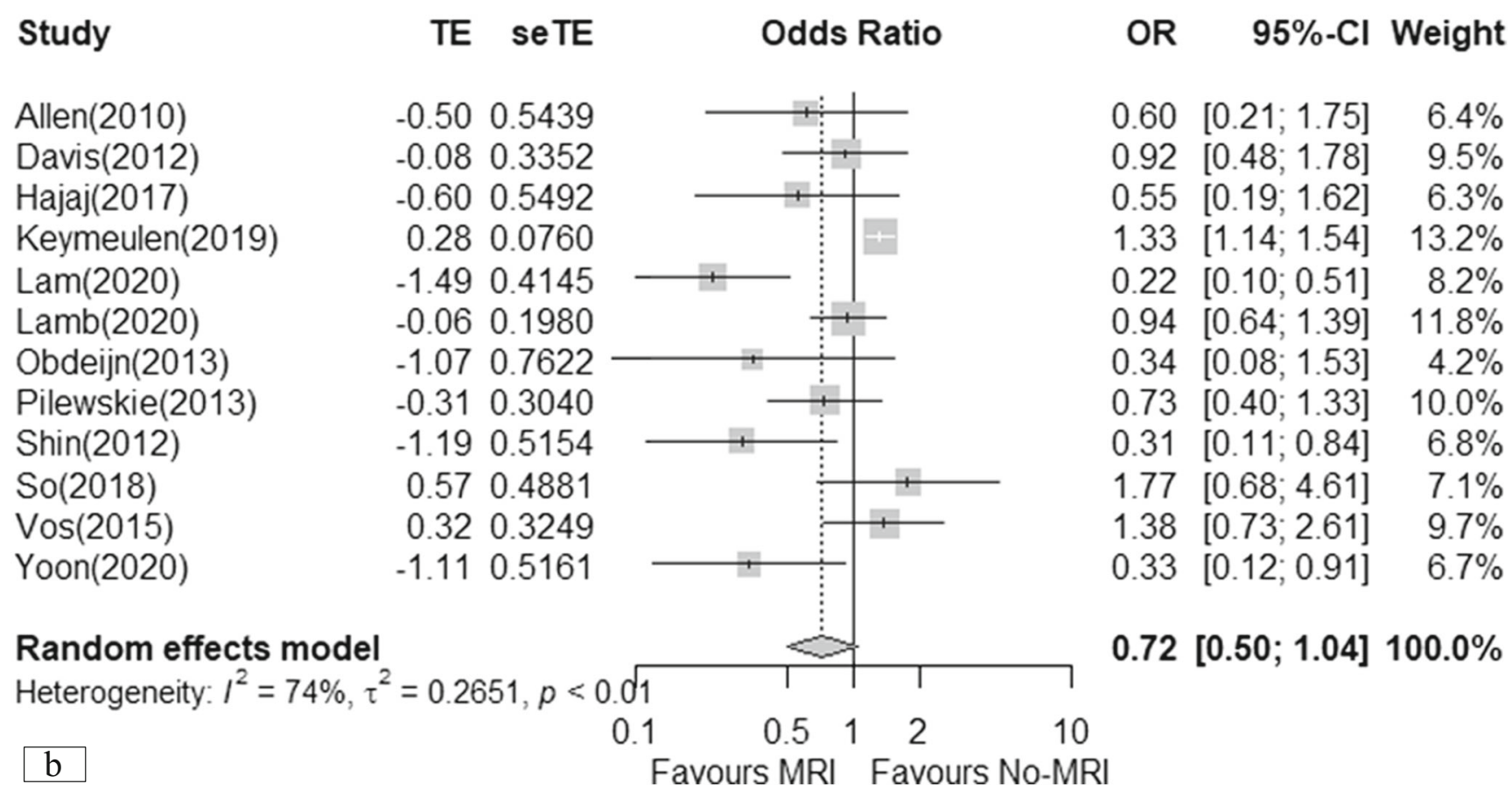

Fig. 3 Meta-analyses of re-operation rate. a Randomised clinical trial; b cohort studies (prospective and retrospectives)

different standards of care due to the progress in treatment quality over time $[23,24,26]$.

For the assessment of the certainty of evidence, we rated down for risk of bias for all outcomes, for inconsistency in most estimates informed by observational studies, and for imprecision for locoregional recurrence, positive margins estimated from RCTs, and for re-operation estimates from both RCTs and observational evidence (Table 2 and Supplementary table S5).

\section{Discussion}

\section{Main findings}

Our review suggests that pre-operative breast MRI for DICS lesions may have no meaningful impact on surgical outcomes or on the risk of local recurrence. RCTs showed that MRI had little to no effect on initial BCS or total mastectomies, a finding that was consistent also with the results from observational studies. For re-operations, there is also uncertainty; the IRCIS trial designed to include only DCIS patients suggested a reduction but with confidence intervals including the opposite effect [21], while the MONET trial showed an increase in a small DCIS subgroup [19]. Among observational studies, Yoon et al, using propensity score matching, suggested a reduction in re-operations [35]. However, another two observational studies providing adjusted estimates did not find a benefit with MRI [30, 32].

The included RCTs had several limitations [46]. The IRCIS trial recruited patients eligible for BCS after mammography, ultrasound and percutaneous biopsy which might have biased mastectomy effect estimates against MRI. This study might also be underpowered as there were meaningful differences in the results between the intention to treat and per protocol analysis [21]. The MONET [19] and COMICE [20] trials randomised women with non- 
Table 2 Summary of findings

\begin{tabular}{|c|c|c|c|c|c|}
\hline \multirow[b]{2}{*}{ Outcomes } & \multirow{2}{*}{$\begin{array}{c}\text { № of participants } \\
\text { (studies) } \\
\text { Follow-up }\end{array}$} & \multirow{2}{*}{$\begin{array}{l}\text { Certainty of the evidence } \\
\text { (GRADE) }\end{array}$} & \multirow{2}{*}{$\begin{array}{l}\text { Relative effect } \\
\qquad(95 \% \mathrm{Cl})\end{array}$} & \multicolumn{2}{|c|}{ Anticipated absolute effects } \\
\hline & & & & $\begin{array}{l}\text { Risk with no additional } \\
\text { MRI }\end{array}$ & $\begin{array}{l}\text { Risk difference with additional } \\
\text { MRI }\end{array}$ \\
\hline Initial breast conserving-surgery - $\mathrm{RCT}^{19,21}$ & $\begin{array}{c}429 \\
(2 \mathrm{RCTs})\end{array}$ & $\begin{array}{l}\oplus \oplus \operatorname{LW}^{\mathrm{a}, \mathrm{b}, \mathrm{c}} \\
\end{array}$ & $\begin{array}{c}\text { RR } 0.95 \\
(0.90 \text { to } 1.00)\end{array}$ & 902 per 1,000 & $\begin{array}{l}45 \text { fewer per } 1,000 \\
\text { (90 fewer to } 0 \text { fewer) }\end{array}$ \\
\hline Initial breast conserving-surgery - Cohorts ${ }^{11,12,22-24,27,32-36}$ & $\begin{array}{c}15121 \\
\text { (11 observational studies) }\end{array}$ & $\begin{array}{l}\oplus \infty_{\text {VERY LOW }}^{\text {d,e,f,g }} \\
\text { VE }\end{array}$ & $\begin{array}{c}\text { OR } 0.49 \\
(0.29 \text { to } 0.82)\end{array}$ & 756 per 1,000 & $\begin{array}{l}153 \text { fewer per } 1,000 \\
\text { (283 fewer to } 38 \text { fewer) }\end{array}$ \\
\hline Proportion of positive margins - $\mathrm{RCT}^{20}$ & $\begin{array}{c}91 \\
(1 \mathrm{RCT})\end{array}$ & $\begin{array}{l}\oplus \bigcup_{\text {VERY LOW }}^{\mathrm{a}, \mathrm{b}, \mathrm{h}, \mathrm{i}} \\
\end{array}$ & $\begin{array}{c}\text { RR } 1.58 \\
(0.85 \text { to } 2.92)\end{array}$ & 250 per 1,000 & $\begin{array}{l}145 \text { more per } 1,000 \\
\text { ( } 38 \text { fewer to } 480 \text { more) }\end{array}$ \\
\hline Proportion of positive margins - Cohorts ${ }^{11,22,25,26,28,32,33,35}$ & $\begin{array}{c}9126 \\
\text { (8 observational studies) }\end{array}$ & $\begin{array}{l}\oplus O O_{\text {d,ef,h,j }} \\
\text { VERY LOW }\end{array}$ & $\begin{array}{c}\text { OR } 0.91 \\
(0.85 \text { to } 1.21)\end{array}$ & 205 per 1,000 & $\begin{array}{l}15 \text { fewer per } 1,000 \\
\text { (54 fewer to } 34 \text { more) }\end{array}$ \\
\hline Re-operation rate - $\mathrm{RCT}^{19,21}$ & $\begin{array}{c}377 \\
(2 \mathrm{RCTs})\end{array}$ & $\begin{array}{l}\oplus{ }_{0} \\
\text { VERY LOW }\end{array}$ & $\begin{array}{c}\text { RR } 1.02 \\
(0.56 \text { to } 1.84)\end{array}$ & 297 per 1,000 & $\begin{array}{c}6 \text { more per } 1,000 \\
(131 \text { fewer to } 249 \text { more })^{j}\end{array}$ \\
\hline Re-operation rate - Cohorts ${ }^{30,32,35}$ & $\begin{array}{c}856 \\
\text { (3 observational studies) }\end{array}$ & $\begin{array}{l}\oplus \oplus \bigoplus \\
\text { LOW }^{i, 1}\end{array}$ & $\begin{array}{c}\text { aOR } 0.96 \\
(0.36 \text { to } 2.61)^{j}\end{array}$ & 164 per 1,000 & $\begin{array}{l}6 \text { fewer per } 1,000 \\
\text { (99 fewer to } 175 \text { more) }\end{array}$ \\
\hline Total mastectomy rate - $\mathrm{RCT}^{19,21}$ & $\begin{array}{c}429 \\
(2 \mathrm{RCTs})\end{array}$ & $\begin{array}{l}\oplus \infty O^{a, b, i} \\
\text { VERY LOW }\end{array}$ & $\begin{array}{c}\text { RR } 0.91 \\
(0.65 \text { to } 1.27)\end{array}$ & 234 per 1,000 & $\begin{array}{l}21 \text { fewer per } 1,000 \\
\text { (82 fewer to } 63 \text { more) }\end{array}$ \\
\hline Total mastectomy rate - Cohorts ${ }^{12,22,23,25,32-35}$ & $\begin{array}{c}12283 \\
\text { (8 observational studies) }\end{array}$ & $\begin{array}{l}\oplus \overbrace{}^{\mathrm{d}, \mathrm{e}, \mathrm{j}, \mathrm{j}} \\
\text { VERY LOW }\end{array}$ & $\begin{array}{c}\text { OR } 1.58 \\
(1.00 \text { to } 2.48)\end{array}$ & 297 per 1,000 & $\begin{array}{l}103 \text { more per } 1,000 \\
\text { ( } 0 \text { more to } 215 \text { more) }\end{array}$ \\
\hline $\begin{array}{l}\text { Disease free survival (inferred from locoregional recurrence) - } \\
\qquad \text { Cohorts }^{28}\end{array}$ & $\begin{array}{c}2212 \\
\text { (1 observational study) }\end{array}$ & $\begin{array}{l}\oplus \underbrace{\infty} \\
\text { VERY LOW }\end{array}$ & $\begin{array}{l}\text { aHR } 1.18 \\
(0.79 \text { to } 1.76)\end{array}$ & 85 per 1,000 & $\begin{array}{l}15 \text { more per } 1,000 \\
\text { (17 fewer to } 60 \text { more) }\end{array}$ \\
\hline Treatment change - Cohort ${ }^{12,21,26,34,35,38-41}$ & (10 observational studies) & $\begin{array}{l}\oplus \oplus \operatorname{LOW}^{t, q} \\
\text { L }^{-1}\end{array}$ & $\begin{array}{l}\text { The pooled proport } \\
\text { 1560). }\end{array}$ & tment change was $18 \%$ & $95 \% \mathrm{Cl} 12 \%$ to $22 \%$; $\left.\left.\right|^{2} 79 \%\right)$. ( $N=$ \\
\hline
\end{tabular}

${ }^{*}$ The risk in the intervention group (and its $95 \%$ confidence interval) is based on the assumed risk in the comparison group and the relative effect of the intervention (and its $95 \% \mathrm{Cl}$ ).

Cl: Confidence interval; RR: Risk ratio; OR: Odds ratio; aHR: Adjusted hazard Ratio

${ }^{a}$ Risk of bias. The intervention (preoperative MRI) was not feasible to be blinded which led to high risk of performance bias, potentially influencing surgeons' treatment plans

${ }^{\mathrm{b}}$ Risk of bias. There was also a potential risk of imbalance of prognostic factors, due to the inclusion of results from a very small subgroup of participants in some RCTs

${ }^{\mathrm{c}}$ Indirectness. Initial BCS was considered an intermediate outcome, as women could have received re-excision or a mastectomy depending on the presence of positive margins in the excised specimen

${ }^{\mathrm{d}}$ Risk of bias. In some cohort studies, the comparison was between arms over different periods of time (secular bias)

${ }^{\mathrm{e}}$ Risk of bias. Most observational studies reported unadjusted estimates

${ }^{\mathrm{f}}$ Inconsistency. Potentially important and unexplained heterogeneity across included studies

${ }^{\mathrm{g}}$ Other considerations. Although there is an observed large effect, there is a very serious risk of bias concern and the estimate is imprecise; thus, we did not upgrade the certainty of evidence

${ }^{\mathrm{h}}$ Risk of bias. The definition of positive margins was variable across clinical centres potentially introducing misclassification bias

${ }^{\mathrm{i}}$ Imprecision. The anticipated absolute effects associated to the intervention go from potential benefit to potential harm

${ }^{\mathrm{j}}$ Imprecision. There is imprecision of the anticipated absolute effects with the intervention but it is likely due to heterogeneity across studies

${ }^{\mathrm{k}}$ Only estimates from studies reporting adjusted ORs are included as the results were different from those unadjusted

${ }^{1}$ Risk of bias. Both studies reported adjusted estimates, although one study did not include tumour size as a pre-defined confounding variable in the analysis. Additionally, there was no information about the time the MRI exam was requested

${ }^{\mathrm{m}}$ Risk of bias. Only patients who received breast-conserving surgery were included. There was potential selection bias as those with more aggressive treatments after MRI were not included. Potential over adjustment in the multivariate analysis as positive margins and number of excisions may be in the casual pathway to disease recurrence

${ }^{\mathrm{n}}$ Indirectness. A proportion of patients had breast MRI performed after lumpectomy or at re-excision stage

${ }^{\circ}$ Indirectness. Serious indirectness as locoregional recurrence is considered a surrogate of disease-free survival

${ }^{\mathrm{p}}$ Imprecision. The absolute effect of the intervention ranged from significant benefit to significant harm

${ }^{\mathrm{q}}$ Risk of bias. Decision to request breast MRI (after mammography and ultrasound) might be associated to the decision to change the initial plan, independent of MRI results

palpable or BIRADS 3-5 lesions respectively, while women with DCIS were only a small fraction of them. Moreover, these RCTs reported difficulties in the acquisition of MIR images at $3 \mathrm{~T}$ before randomisation [19], underwent MRI prior to biopsy which is not considered standard of care [19] and guided biopsies to verify MRI findings were not available in all cases [20].

\section{Our results in the context of previous research}

A systematic review including a lower number of studies than our review showed that preoperative breast MRI in patients with DCIS was not associated with an improvement in surgical outcomes [47]. Similar results were also observed in patients with invasive cancer [48-51], with a systematic review 


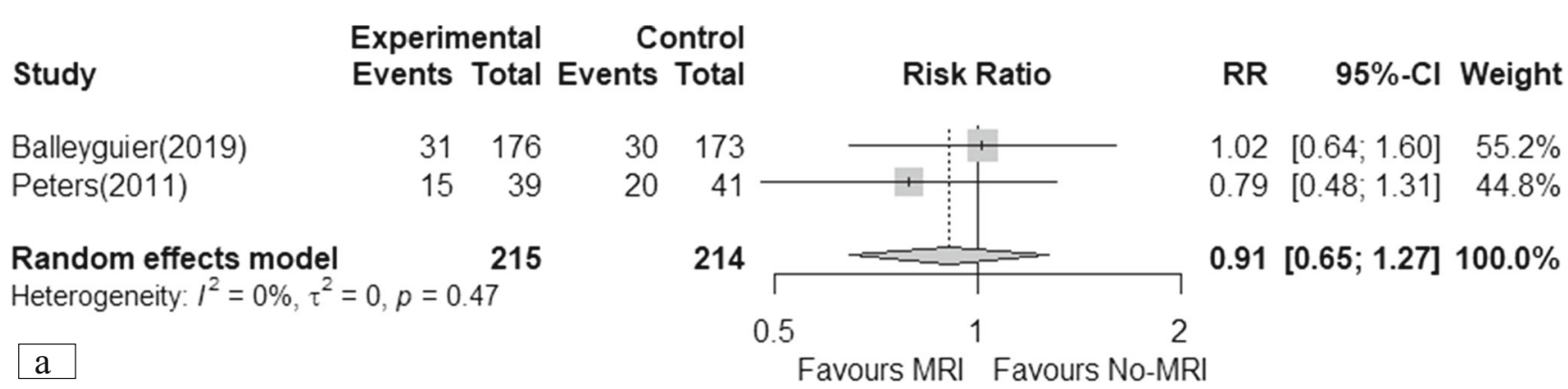

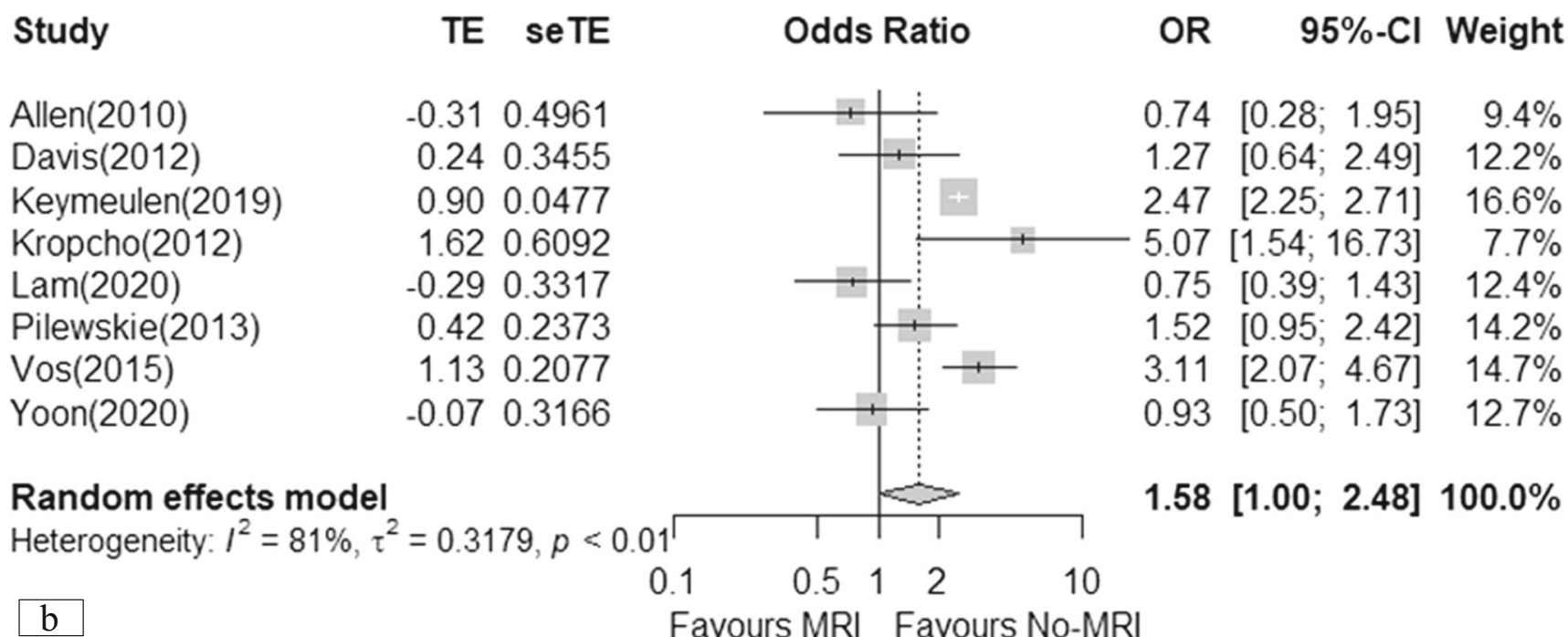

Fig. 4 Meta-analyses of total mastectomy. a Randomised clinical trial; $\mathbf{b}$ cohort studies (prospective and retrospectives)

showing that MRI increased mastectomy rates [50] and one individual person-data meta-analysis reporting that MRI does not reduce the risk of local recurrence or distant recurrence in these patients [51].

One potential explanation for the lack of benefit on surgical outcomes might be a limited specificity of MRI in patients with DCIS, and variable positive predictive value from 25 to $84 \%$ [52]. Previous data has shown that MRI, compared to histopathology, tends to overestimate the size of pure DCIS lesions and has moderate correlation with pathologically measured tumour size $(r=0.74)$ [53, 54]. This limitation could impact on having more aggressive treatments than needed, but not on the number of re-excisions. Furthermore, it should have only hampered older studies where biopsies were not performed in all new lesions identified by MRI and patients frequently went directly to reassessment of the surgical treatment plan.

An important factor is to ensure MRI images were adequately acquired. The ACR Breast MRI Accreditation Program began accrediting facilities in 2010 [55], requiring adequate magnetic field strength (1 T or higher) and gradient, bilateral breast coil enabling prone positioning and good fat suppression [55]. Older studies might be prone to unstandardised procedures as accreditation was not uniformly implemented. Currently, most facilities perform 1.5 T MRI, but the use of 3-T magnetic field has increased [56]. As some studies suggest, despite some technical limitations, $3 \mathrm{~T}$ could provide higher correlation with DCIS pathology size compared to $1.5 \mathrm{~T}$, therefore obtaining higher image quality scores and better differential diagnosis of enhancing lesions [57]. Another study, including 20 DCIS lesions, found that size correlation between MRI images and pathology was higher with $3 \mathrm{~T}$ [58]. Most studies in our review used 1.5 T; thus, further studies are needed to assess the clinical impact of $3 \mathrm{~T}$.

To provide an optimal accuracy, breast MRI should ideally provide high spatial and temporal resolution [59]; however, conventional MRI methods cannot deliver both and usually prioritise spatial resolution [59]. To solve this issue, recent technical advancements have focused on accelerating data acquisition. Morrison et al described a method that provided sixtimes faster effective temporal resolution and the same high spatial resolution of standard MRI [60]. Goto et al improved the temporal resolution with preservation of spatial resolution using ultra-fast DCE-MRI to differentiate malignant and 
benign lesions [61]. As new techniques are developed, the performance of MRI in the preoperative setting could improve.

\section{Limitations and strengths}

We included only English language articles although we included a larger number of studies than previous reviews. We could not explore the effect of MRI in some relevant patient subgroups as this data was not available. Our results are hampered by the low to very low certainty of the evidence found for the included outcomes.

Our review has several strengths. We included outcomes that were of interest for women, clinicians and policy makers when facing the decision of implementing or recommending preoperative MRI, and used rigorous methods including the GRADE approach to rate the certainty of the evidence.

\section{Implications for practice and research}

Patients and clinicians should be aware that although breast MRI for pre-operative assessment may improve the morphological description of DCIS lesions, we did not find evidence to suggest an improvement of surgical outcomes. In fact, observational evidence, although of very low certainty, may suggest that preoperative MRI could lead to more aggressive treatments. Also, MRI-guided biopsy to confirm new lesions or important expansions of the detected lesions is not always feasible or accessible. From a health system perspective, preoperative MRI implies greater resource use [62, 63], and given the uncertain potential benefits, the use of MRI has probably limited interest [64].

Given the uncertain evidence, there is a need for conducting well-powered RCTs assessing the role of preoperative MRI during treatment planning in patients with DCIS lesions incorporating new advancements in MRI imaging acquisition, securing the availability of experienced imaging readers and biopsy confirmation of new lesions.

Supplementary Information The online version contains supplementary material available at https://doi.org/10.1007/s00330-021-07873-2.

Acknowledgements The authors would like to sincerely thank all members of the Guidelines Development Group of the European Commission Initiative on Breast Cancer for their participation in the discussions generated by this systematic review which led to the different recommendations they developed in the European Guidelines on Breast Cancer Screening and diagnosis (https://healthcare-quality.jrc. ec.europa.eu/european-breast-cancer-guidelines).

Funding The systematic review was carried out by Iberoamerican Cochrane Collaboration under the Framework contract 443094 for procurement of services between the European Commission's Joint Research Centre and Asociación Colaboración Cochrane Iberoamericana.

\section{Declarations}

Guarantor The scientific guarantor of this publication is Carlos CaneloAybar.

Conflict of interest Elena Parmelli and Zuleika Saz-Parkinson are current employees of the Joint Research Centre, European Commission. Carlos Canelo-Aybar, Pablo Alonso-Coello, and David Rigau are employees of the Iberoamerican Cochrane Collaboration. Axel Gräwingholt, Annette Lebeau, Elsa Pérez Gómez and Miranda Langendam are members of the ECIBC Guidelines Development Group. Paolo Giorgi Rossi, as principal investigator of an independent study, funded by the Italian Ministry of Health, conducted negotiations with Hologic to obtain reagents at reduced price or for free; the reagents have not been used by Paolo Giorgi Rossi's institutions; he is also member of the ECIBC Guidelines Development Group. Jessica Hanae ZafraTanaka and Alvaro Taype-Rondan were employees of the Institute for Health Technology Assessment and Research (IETSI) from the Peruvian Social Security at the time the study took place.

Statistics and biometry No complex statistical methods were necessary for this paper.

Informed consent Written informed consent was not required for this study because it is a systematic review.

Ethical approval Institutional Review Board approval was not required because it is a systematic review.

Study subjects or cohorts overlap The studies included in this systematic review were all already published elsewhere. Their references and characteristics are reported within the manuscript.

\section{Methodology}

- retrospective (systematic review of already published studies)

- performed at one institution

Open Access This article is licensed under a Creative Commons Attribution 4.0 International License, which permits use, sharing, adaptation, distribution and reproduction in any medium or format, as long as you give appropriate credit to the original author(s) and the source, provide a link to the Creative Commons licence, and indicate if changes were made. The images or other third party material in this article are included in the article's Creative Commons licence, unless indicated otherwise in a credit line to the material. If material is not included in the article's Creative Commons licence and your intended use is not permitted by statutory regulation or exceeds the permitted use, you will need to obtain permission directly from the copyright holder. To view a copy of this licence, visit http://creativecommons.org/licenses/by/4.0/.

\section{References}

1. Ferlay J, Ervik M, Lam F et al (2018) Global Cancer Observatory: cancer today. Lyon, France: International Agency for Research on 
Cancer. Available from: https://gco.iarc.fr/today. Accessed 2507 2019

2. Schmale I, Liu S, Rayhanabad J, Russell CA, Sener SF (2012) Ductal carcinoma in situ (DCIS) of the breast: perspectives on biology and controversies in current management. J Surg Oncol 105: 212-220

3. Kerlikowske K (2010) Epidemiology of ductal carcinoma in situ. J Natl Cancer Inst Monogr 2010:139-141

4. Barrio AV, Van Zee KJ (2017) Controversies in the treatment of ductal carcinoma in situ. Annu Rev Med 68:197-211

5. Jansen CHP, Perera D, Wiethoff AJ et al (2017) Contrast-enhanced magnetic resonance imaging for the detection of ruptured coronary plaques in patients with acute myocardial infarction. PLoS One 12: e0188292

6. Mann RM, Kuhl CK, Moy L (2019) Contrast-enhanced MRI for breast cancer screening. J Magn Reson Imaging 50:377-390

7. Houssami N, Ciatto S, Macaskill P et al (2008) Accuracy and surgical impact of magnetic resonance imaging in breast cancer staging: systematic review and meta-analysis in detection of multifocal and multicentric cancer. J Clin Oncol 26:3248-3258

8. Tajima CC, de Sousa LLC, Venys GL, Guatelli CS, Bitencourt AGV, Marques EF (2019) Magnetic resonance imaging of the breast: role in the evaluation of ductal carcinoma in situ. Radiol Bras 52(1):43-47

9. Menezes GL, Knuttel FM, Stehouwer BL, Pijnappel RM, van den Bosch MA (2014) Magnetic resonance imaging in breast cancer: a literature review and future perspectives. World J Clin Oncol 5:61

10. Albert ML, Gao Y, Moy L (2016) Role of breast MRI in patients with newly diagnosed breast cancer. Curr Breast Cancer Rep 8:8089

11. Itakura K, Lessing J, Sakata T et al (2011) The impact of preoperative magnetic resonance imaging on surgical treatment and outcomes for ductal carcinoma in situ. Clin Breast Cancer 11:33-38

12. Pilewskie M, Kennedy C, Shappell C et al (2013) Effect of MRI on the management of ductal carcinoma in situ of the breast. Ann Surg Oncol 20:1522-1529

13. Schunemann HJ, Lerda D, Dimitrova N et al (2019) Methods for development of the European Commission Initiative on Breast Cancer Guidelines: recommendations in the era of guideline transparency. Ann Intern Med. https://doi.org/10.7326/M18-3445

14. Higgins JP, Altman DG, Gøtzsche PC et al (2011) The Cochrane Collaboration's tool for assessing risk of bias in randomised trials. BMJ 343:d5928

15. Sterne JA, Hernán MA, Reeves BC et al (2016) ROBINS-I: a tool for assessing risk of bias in non-randomised studies of interventions. BMJ 355:i4919

16. Nyaga VN, Arbyn M, Aerts M (2014) Metaprop: a Stata command to perform meta-analysis of binomial data. Arch Public Health 72: 39

17. Balshem H, Helfand M, Schünemann HJ et al (2011) GRADE guidelines: 3. Rating the quality of evidence. J Clin Epidemiol 64: 401-406

18. Schunemann HJ, Cuello C, Akl EA et al (2019) GRADE guidelines: 18. How ROBINS-I and other tools to assess risk of bias in nonrandomized studies should be used to rate the certainty of a body of evidence. J Clin Epidemiol 111:105-114

19. Peters N, Van Esser S, Van Den Bosch M et al (2011) Preoperative MRI and surgical management in patients with nonpalpable breast cancer: the MONET-randomised controlled trial. Eur J Cancer 47: 879-886

20. Turnbull LW, Brown SR, Olivier C et al (2010) Multicentre randomised controlled trial examining the cost-effectiveness of contrast-enhanced high field magnetic resonance imaging in women with primary breast cancer scheduled for wide local excision (COMICE). Health Technol Assess 14:1-182
21. Balleyguier C, Dunant A, Ceugnart L et al (2019) Preoperative breast magnetic resonance imaging in women with local ductal carcinoma in situ to optimize surgical outcomes: results from the randomized phase III trial IRCIS. J Clin Oncol:18.00595

22. Allen LR, Lago-Toro CE, Hughes JH et al (2010) Is there a role for MRI in the preoperative assessment of patients with DCIS? Ann Surg Oncol 17:2395-2400

23. Davis KL, Barth RJ, Gui J, Dann E, Eisenberg B, Rosenkranz K (2012) Use of MRI in preoperative planning for women with newly diagnosed DCIS: risk or benefit? Ann Surg Oncol 19:3270-3274

24. Hajaj M, Karim A, Pascaline S, Noor L, Patel S, Dakka M (2017) Impact of MRI on high grade ductal carcinoma insitu (HG DCIS) management, are we using the full scope of MRI? Eur J Radiol 95: 271-277

25. Kropcho LC, Steen ST, Chung AP, Sim MS, Kirsch DL, Giuliano AE (2012) Preoperative breast MRI in the surgical treatment of ductal carcinoma in situ. Breast J 18:151-156

26. Obdeijn I-M, Tilanus-Linthorst MM, Spronk S et al (2013) Preoperative breast MRI can reduce the rate of tumor-positive resection margins and reoperations in patients undergoing breastconserving surgery. AJR Am J Roentgenol 200:304-310

27. Onega T, Weiss JE, Goodrich ME et al (2017) Relationship between preoperative breast MRI and surgical treatment of nonmetastatic breast cancer. J Surg Oncol 116:1008-1015

28. Pilewskie M, Olcese C, Eaton A et al (2014) Perioperative breast MRI is not associated with lower locoregional recurrence rates in DCIS patients treated with or without radiation. Ann Surg Oncol 21:1552-1560

29. Shin H-C, Han W, Moon H-G et al (2012) Limited value and utility of breast MRI in patients undergoing breast-conserving cancer surgery. Ann Surg Oncol 19:2572-2579

30. So A, De La Cruz LM, Williams AD et al (2018) The impact of preoperative magnetic resonance imaging and lumpectomy cavity shavings on re-excision rate in pure ductal carcinoma in situ-a single institution's experience. J Surg Oncol 117:558-566

31. Vapiwala N, Hwang WT, Kushner CJ, Schnall MD, Freedman GM, Solin LJ (2017) No impact of breast magnetic resonance imaging on 15-year outcomes in patients with ductal carcinoma in situ or early-stage invasive breast cancer managed with breast conservation therapy. Cancer 123:1324-1332

32. Vos E, Voogd AC, Verhoef C, Siesling S, Obdeijn I-M, Koppert LB (2015) Benefits of preoperative MRI in breast cancer surgery studied in a large population-based cancer registry. Br J Surg 102: $1649-1657$

33. Keymeulen K, Geurts SME, Lobbes MBI et al (2019) Populationbased study of the effect of preoperative breast MRI on the surgical management of ductal carcinoma in situ. Br J Surg 106:1488-1494

34. Lam DL, Smith J, Partridge SC et al (2020) The impact of preoperative breast MRI on surgical management of women with newly diagnosed ductal carcinoma in situ. Acad Radiol 27:478-486

35. Yoon GY, Choi WJ, Kim HH, Cha JH, Shin HJ, Chae EY (2020) Surgical outcomes for ductal carcinoma in situ: impact of preoperative MRI. Radiology 295:296-303

36. Lamb LR, Oseni TO, Lehman CD, Bahl M (2020) Pre-operative MRI in patients with ductal carcinoma in situ: is MRI useful for identifying additional disease? Eur J Radiol 129:109130

37. Lee J, Jung JH, Kim WW et al (2016) The role of preoperative breast magnetic resonance (MR) imaging for surgical decision in patients with triple-negative breast cancer. J Surg Oncol 113:12-16

38. Hlubocky J, Bhavnagri S, Swinford A, Mitri C, Rebner M, Pai V (2018) Does the use of pretreatment MRI change the management of patients with newly diagnosed breast cancer? Breast J 24:309 313

39. Pettit K, Swatske ME, Gao F et al (2009) The impact of breast MRI on surgical decision-making: are patients at risk for mastectomy? J Surg Oncol 100:553-558 
40. Besharat Sara KM, Azadeh J, Nasser M (2018) Influence of preoperative magnetic resonance imaging in surgical planning for breast cancer. Int J Cancer Manag 11:e81459

41. Duygulu G, Oktay A, Bilgen IG, Kapkaç M, Zekioglu O (2012) The role of breast MRI in planning the surgical treatment of breast cancer. Diagn Interv Radiol 18:460

42. Solin LJ, Orel SG, Hwang WT, Harris EE, Schnall MD (2008) Relationship of breast magnetic resonance imaging to outcome after breast-conservation treatment with radiation for women with earlystage invasive breast carcinoma or ductal carcinoma in situ. J Clin Oncol 26:386-391

43. Skov BG, Braendstrup O, Hirsch FR, Lauritzen AF, Nielsen HW, Skov T (1994) Are pathologists biased by clinical information?: a blinded cross-over study of the histopathological diagnosis of mesothelial tumours versus pulmonary adenocarcinoma. Lung Cancer 11:365-372

44. Cui L, Hung HM, Wang SJ, Tsong Y (2002) Issues related to subgroup analysis in clinical trials. J Biopharm Stat 12:347-358

45. Chu R, Walter SD, Guyatt $\mathrm{G}$ et al (2012) Assessment and implication of prognostic imbalance in randomized controlled trials with a binary outcome-a simulation study. PLoS One 7:e36677

46. Pinker K (2020) Preoperative MRI improves surgical planning and outcomes for ductal carcinoma in situ. Radiology 295:304-306

47. Fancellu A, Turner RM, Dixon JM, Pinna A, Cottu P, Houssami N (2015) Meta-analysis of the effect of preoperative breast MRI on the surgical management of ductal carcinoma in situ. Br J Surg 102: 883-893

48. Parsyan A, Alqahtani A, Mesurolle B, Meterissian S (2013) Impact of preoperative breast MRI on surgical decision making and clinical outcomes: a systematic review. World J Surg 37:2134-2139

49. Houssami N, Turner R, Morrow M (2013) Preoperative magnetic resonance imaging in breast cancer: meta-analysis of surgical outcomes. Ann Surg 257:249-255

50. Houssami N, Turner RM, Morrow M (2017) Meta-analysis of preoperative magnetic resonance imaging (MRI) and surgical treatment for breast cancer. Breast Cancer Res Treat 165:273-283

51. Houssami N, Turner R, Macaskill P et al (2014) An individual person data meta-analysis of preoperative magnetic resonance imaging and breast cancer recurrence. J Clin Oncol 32:392-401

52. Brem RF, Fishman M, Rapelyea JA (2007) Detection of ductal carcinoma in situ with mammography, breast specific gamma imaging, and magnetic resonance imaging: a comparative study. Acad Radiol 14:945-950
53. Baur A, Bahrs SD, Speck S et al (2013) Breast MRI of pure ductal carcinoma in situ: sensitivity of diagnosis and influence of lesion characteristics. Eur J Radiol 82:1731-1737

54. Schouten van der Velden AP, Schlooz-Vries MS, Boetes C, Wobbes T (2009) Magnetic resonance imaging of ductal carcinoma in situ: what is its clinical application? A review. Am J Surg 198: 262-269

55. Hendrick RE (2014) High-quality breast MRI. Radiol Clin North Am 52:547-562

56. Soher BJ, Dale BM, Merkle EM (2007) A review of MR physics: 3 T versus 1.5 T. Magn Reson Imaging Clin N Am 15:277-290

57. Kuhl CK, Jost P, Morakkabati N, Zivanovic O, Schild HH, Gieseke $\mathrm{J}$ (2006) Contrast-enhanced MR imaging of the breast at 3.0 and 1.5 $\mathrm{T}$ in the same patients: initial experience. Radiology 239:666-676

58. Rahbar H, DeMartini WB, Lee AY, Partridge SC, Peacock S, Lehman CD (2015) Accuracy of $3 \mathrm{~T}$ versus $1.5 \mathrm{~T}$ breast MRI for pre-operative assessment of extent of disease in newly diagnosed DCIS. Eur J Radiol 84:611-616

59. Kuhl C (2007) The current status of breast MR imaging. Part I. Choice of technique, image interpretation, diagnostic accuracy, and transfer to clinical practice. Radiology 244:356-378

60. Morrison CK, Henze Bancroft LC, DeMartini WB et al (2017) Novel high spatiotemporal resolution versus standard-of-care dynamic contrast-enhanced breast MRI: Comparison of Image Quality. Invest Radiol 52:198-205

61. Goto M, Sakai K, Yokota H et al (2019) Diagnostic performance of initial enhancement analysis using ultra-fast dynamic contrastenhanced MRI for breast lesions. Eur Radiol 29:1164-1174

62. Pataky RE, Baliski CR (2016) Reoperation costs in attempted breast-conserving surgery: a decision analysis. Curr Oncol 23: 314-321

63. Onega T, Tosteson AN, Weiss J et al (2016) Costs of diagnostic and preoperative workup with and without breast MRI in older women with a breast cancer diagnosis. BMC Health Serv Res 16:76

64. Kandel M, Dunant A, Balleyguier C, Bonastre J (2020) Costeffectiveness of preoperative magnetic resonance imaging to optimize surgery in ductal carcinoma in situ of the breast. Eur J Radiol 129:109058

Publisher's note Springer Nature remains neutral with regard to jurisdictional claims in published maps and institutional affiliations. 